\title{
3ZABEPSS
}

\section{AS COTAS NA PÓS-GRADUAÇÃO: ORIENTAÇÕES DA ABEPSS PARA O AVANÇO DO DEBATE ${ }^{1}$}

Tendo em vista o compromisso ético-político e acadêmico-histórico da ABEPSS e a consonante defesa dos princípios profissionais, com a defesa da superação de todas as formas de exploração e opressões. Com o entendimento de que a questão étnicoracial não pode ser compreendidae tratada de formadesvinculada dos processos de produção e reprodução da vida social, tomamos como pressuposto que "o racismo não é apenas um problema ético, uma categoria jurídica ou um dado psicológico. $O$ racismo é uma relação social, que se estrutura política e economicamente" (ALMEIDA, 2016, p. 23). A ABEPSS assume a posição de orientação às unidades formadoras em relação às cotas na Pós-Graduação em Serviço Social. ${ }^{2}$

Apoia-se ainda no fato de que na história da nossa formação social, particularmente no que diz respeito às relações raciais brasileiras, as suas particularidades históricosociais ganharam contornos próprios dimensionando as expressões da questão social.

As particularidades destas implicações político-sociais para os descendentes dos povos escravizados no Brasil, além de reconhecidas,não devem ser desprezadas. As marcas do racismo revelam-se nas variadas pesquisas e indicadores sociais, como se pode observar:

Em 2009,"das cerca de 11 milhões de famílias beneficiárias do Programa Bolsa Família [...], em todo o país, cerca de 7,3 milhões de famílias tinham por titular pessoas de cor ou raça [preta] [...] e parda" (PAIXÃO, et al., 2010, p. 133). Pesquisa do IBGE (2011, p. 53) aponta que nas taxas de analfabetismo das pessoas de 15 anos ou

\footnotetext{
${ }^{1}$ Ação deliberada no planejamento da gestão "Quem é de luta, resiste!" (biênio 2017-2018)com a proposição de criação da Comissão de Trabalho sobre cotas articulada ao GTP que trata da questão. $O$ grupo se debruçou na elaboração desse documento inicial, no primeiro semestre de 2017, com o objetivo de fomentar a discussão sobre cotas nos PPG's da área. O mesmo grupo assume a tarefa de realizar o levantamento sobre os programas de pós-graduação em Serviço Social do país que aderiram ao sistema de cotas étnico-raciais nos processos de seleção e as iniciativas de ampliação do debate sobre as ações afirmativas neste universo da pós-graduação.

A Comissão Temporária de Trabalho (CTT) contou com as seguintes membras:Márcia Campos Eurico (PUC-SP), Suellen Cruz (UFES), Tereza Cristina Santos Martins (UFS) e João Paulo Valdo (UFF/Niterói). Documento aprovado na executiva nacional da ABEPSS em julho de 2017.

${ }^{2}$ Tanto a ABEPSS, a partir de deliberação na Assembleia Ordinária da entidade na ocasião do ENPESS de 2014, sobre a incorporação da temática de gênero, raça/etnia e sexualidadesna formação profissional do Serviço Social, como o conjunto CFESS/CRESS, que deliberou no Encontro Nacional de 2010 sobre a posição favorável da categoria às políticas afirmativas, conformam posicionamentos coletivos que reforçam essas assertivas.
}

DOI 10.22422/temporalis.2018v18n36417-419 


\section{temporalis}

mais de idade, "tanto pretos (14,4\%) quanto pardos (13,0\%) mostram um percentual de analfabetismo quase três vezes maior do que o dos brancos (5,9\%)". Assim, pobreza e não acesso a educação expressam implicações sociais que atingem diretamente a classe trabalhadora negra desse país.

Os dados do censo do IBGE (2011) contabilizaram em 2010 uma população brasileira superior a 190 milhões de habitantes. As informações relativas aos números de brasileiros (as) por curso mais elevado concluído na área da educação revelam a desigualdade racial enquanto uma marca das relações raciais no Brasil. No nível mais elementar do ensino fundamental e faixa etária adequada há certo equilíbrio com $51 \%$ de negros (as), 47,6 \% de brancos (as) e 1,4 de amarelos (as) /indígenas."Segundo o censo, em 2000 apenas 1,7\% da população brasileira frequentava o ensino superior ( $0,7 \%$ da população negra e 2,5\% da população branca).Em 2010, embora a frequência bruta tenha aumentado (3,3\% da população), a desigualdade persiste (2,3\% negros $4,3 \%$ brancos) " (SILVA, 2013, p.20).

Quanto maior o nível de escolaridade, mais visível é a desigualdade. Em relação aos cursos de mestrado e doutorado há que se destacar que $80,7 \%$ dos estudantes neste nível é branca, $17,1 \%$ é negra e 2,2 \% corresponde aos grupos populacionais amarelos e indígenas(SILVA, 2013).

Diante da complexidade das relações raciais no Brasil, profundamente desiguais, a aprovação de ações afirmativas no âmbito da pós-graduação é uma medida importante, de caráter reparatório frente às atrocidades cometidas contra a população negra.As ações afirmativas são definidas como um conjunto de medidas legais e políticas que tem por objetivo eliminar as diversas formas de discriminação que cerceiam as oportunidades de determinados grupos na sociedade. O que se aplica em relação às cotas no nível de pós-graduação ao possibilitar a aplicação de medidas que permitam evitar que a discriminação racial ocorra no momento do acesso e durante a permanência deste grupo na universidade.

O debate sobre a questão étnico-racial e as ações visando à erradicação do racismo e da discriminação racial é uma tarefa de toda sociedade,na medida em que a luta contra o racismo é o esteio da luta anticapitalista. Isso porque "o racismo é uma ideologia que sustenta a exploração capitalista” (BORGES, 2016, p. 49).

As políticas afirmativas devem se desenvolver nas Instituições de Ensino Superior públicas e privadas, desconstruindo práticas que por séculos reproduzem o racismo institucional. Diante da realidade de desigualdades étnico-raciais a posição da ABEPSS se justifica pela necessidade de democratizar todas as modalidades de ensino e pesquisa no país. Esse posicionamento toma ainda como referência o pressuposto de que a democratização do ensino de pós-graduação em Serviço Social deve assegurar tanto a ampliação do acesso e da permanência com qualidade como a ampliação dos espaços de participação e tomadas de decisão coletivas, de modo a garantir uma universidade pública, universal, gratuita, democrática, presencial, laica e de qualidade. 
Dos 34Programas de Pós-Graduação na área do Serviço Social ${ }^{3}$ em funcionamento, somente dois possuem cotas étnico-raciais (UERJ e UNIFESP) e dois aprovaramcotas para o edital de seleção para 2018 (UnB e UFES), o que evidencia a necessidade de travarmos essa discussão no interior dos nossos PPG's e nos fóruns da ABEPSS, no sentido da aprovação das cotas nos cursos de mestradoe doutorado.

Nessa direção a ABEPSS faz a indicação de que todos os PPG's da área de Serviço Social qualifiquem os dados acerca do público que majoritariamente preenche as vagas nos cursos de mestrado e doutorado com o objetivo de compreender a intrínseca relação entre raça e classe, que impõe barreiras ao acesso e permanência de negros (as) na pós-graduação. Essas informações poderão contribuir ainda, para a ampliação do debate e da produção sobre a questão racialhoje ainda bastante silenciada.

\section{Referências}

ALMEIDA, S. L. Dossiê Marxismo e Questão Racial. Margem esquerda. Artigo.

Revista Boitempo, São Paulo, n. 27, out. 2016.

BORGES, R. Feminismos negros e marxismo: quem deve a quem? Margem esquerda. Artigo. Revista Boitempo, São Paulo, n. 27, out. 2016.

BRASIL. Ministério da Educação. Documento de Área. Serviço Social. Brasília (DF): Coordenação de Aperfeiçoamento de Pessoal de Nível Superior, 2016. Disponível em: http://www.capes.gov.br/images/documentos/Documentos_de_area_2017/32_SSOC docarea_2016.pdf. Acesso em: jul. 2017.

\section{INSTITUTO BRASILEIRO DE GEOGRAFIA E ESTATÍSTICA. Indicadores Sociais}

Municipais: uma análise dos resultados do universo do censo demográfico 2010. Rio de Janeiro, 2011.

PAIXÃO, M. et al. (Orgs.). Relatório Anual das Desigualdades Raciais no Brasil: 2009-2010. Rio de Janeiro: Garamond, 2010.

SILVA, T. D. Panorama social da população negra. In: SILVA, T. D.; GOES, F. L. (Orgs.). Igualdade racial no Brasil: reflexões no Ano Internacional dos Afrodescendentes. Brasília (DF): Instituto de Pesquisa Econômica Aplicada, 2013. Disponível em: <http://www.ipea.gov.br/portal/images/stories/PDFs/livros/livros/livro_igualdade_ra cialbrasilo1.pdf >. Acesso em: 12 jul. 2017.

\footnotetext{
3 Dos 34 programas de pós-graduação hoje em funcionamento, dois são de Economia Doméstica e 32 são de Serviço Social, nesse universo há 18 cursos de doutorado (PUC/RS, PUC/SP, PUC/Rio, UFMA, UFRJ, UFPE, UnB, UNESP, UERJ, UFPE, UFF, FUFPI, UFES, UFV, UEL, UFSC, UCPel, UFRN e UFPA) e 34 cursos de mestrado, todos cursos acadêmicos (COORDENAÇÃO DE APERFEIÇOAMENTO DE PESSOAL DE NÍVEL SUPERIOR, 2016).
} 